\title{
ALGUNAS SOLUCIONES \\ PARA LA INSOLVENCIA DEL DEUDOR EN EL DERECHO MEDIEVAL FRANCÉS
}

\author{
PATRICIA ZAMBRANA MORAL \\ Universidad de Málaga
}

Una de las posibilidades con las que se encontraba el deudor insolvente que no podía hacer frente al pago de sus deudas para satisfacer a sus acreedores era la cesión de bienes. Se trata de una institución que tiene su origen en la cessio bonorum del derecho romano. El creditor era el "régisseur, celui à qui on confie l'administration d'une chose»', mientras que el cesionario, en el latín medieval en Francia, podía conceptuarse como aquel personaje «qui jure suo vel aliqua possessione cedit, is etiam qui ceditur ${ }^{2}$, aunque estimamos preferible hablar de cesionario para referirnos al acreedor y cedente al deudor que lleva a cabo la cesión y es éste el sentido que empleamos (pese a que, en ocasiones, se ha usado el término cesionario para referirse al que realiza la cesión). En lengua provenzal se utilizan los términos cessioun y abandoun para significar la cession francesa, y la forma concreta en que se expresaba en el provenzal y en otros dialectos de la

\footnotetext{
'En el latín medieval en Francia se le atribuye este sentido con la idea de que el creditor es, por tanto, el "curator, cui creditur res aliqua administranda" (Ver W.H. MAIGNE D ARNIS, Lexicon manuale ad scriptores mediae et infimae latinitatis, ex glossariis Carol. Dufresne D. Ducangh., D. P. Carpentanii, Adelungh, et aliorum, in compendium accuratissime redactum, ou Recueil de mots de la basse latinité dressé pour servir à l'intelligence des auteurs, soit sacrès, soit profanes, du Moyen Age, Paris, 1890, p. 634).

'W.H MaIGNE D'ARNIS, Lexicon manuale, p. 479.

"Anuario de Estudios Medievales". 29 (1999)
} 
lengua d'Oc hacer cesión de bienes era faire cessioun y también faire cessioun miserablo ${ }^{3}$.

Fue introducida la cesión de bienes en Francia en el año 1256 por San Luis - aunque es posible que se descubriese, quizás no en sentido estricto, en costumbres o Estatutos municipales anteriores-, encontrando su desarrollo gracias al impulso de monarcas posteriores pese a que nunca hubo una regulación específica y terminada ${ }^{4}$. Los Établissements de Saint Louis ${ }^{5}$ permitían evitar la ejecución personal al deudor que juraba sobre los Evangelios que pagaría sus deudas si mejoraba su fortuna, siempre que vendiese sus inmuebles en cuarenta horas y no se tratase de deudas fiscales. Sin embargo, no fue una medida recibida con agrado por los acreedores, llegando a estar prohibida en algunos lugares (por ejemplo, por Felipe IV en 1296 o por Felipe VI, en Lille en 1340) y no siendo reconocida en muchos textos normativos. Pese a todo, fue ganando terreno y sería regulada en la mayor parte de las costumbres del siglo XIV, adoptando, para evitar los abusos, formalidades humillantes (Costumbre de Salon de 1293) y, a veces, el destierro para el cedente (Estatutos de Arles de fines del siglo XII) ${ }^{6}$. En el año 1401 se promulgó en Francia una norma que prohibía a los compradores de vino el llevar a cabo la cesión de bienes como privilegio a los vendedores de este producto - se solía prohibir para productos adquiridos

\footnotetext{
${ }^{3}$ Fréderic Mistral, Lou Trésor dóu Felibrige ou Dictionnaire Provençal-Français, Paris, 1932 (reed. anastática, Genève-Paris, 1979), vol. I, p. 521.

${ }^{4}$ Véronique DEMARS-SION, Contribution à l'histoire de la faillite: étude sur la cession de biens à la fin de l'Ancien Régime, en "Revue historique de droit français et étranger", LXXV/1 (enero/marzo, 1997), p. 34.

${ }^{5}$ Consideramos mejor la edición francesa de Paul VIOLLET, Établissements de Saint Louis, en 4 vols. Paris, 1881-1886, que la de F. R. P. AKEHURST, The Etablissements de Saint Louis: Thirteenth-Century Law Texts from Tours, Orléans and Paris, trad. y ed. con introducción. Philadelphia, 1996. Ver de VIOLlet, Précis de l'histoire du droit français, accompagné de notions de droit canonique et d'indications bibliographiques, vol. II, La famille, les biens et les contrats, Paris 1886, y reimp. 1966, en un sólo volumen del conjunto de la obra en 804 pp.; Droit privé et sources. Histoire du droit civil français accompagnée de notions de droit canonique et d'indications bibliographiques, Paris, 1893, 942 pp.; Paris, 1905 y $3^{\text {a }}$ ed. reimp. anastática, 1966 y su trabajo sobre Les sources des Établissements de Saint Loluis, Paris, 1877 que en un total de $101 \mathrm{pp}$. recoge el texto de un curso impartido en la Acadèmie des Inscriptions et Belles Lettres el 2 de febrero, y el 2, 9 y 23 de marzo de 1877.

${ }^{6}$ Armand Guillon, Essai historique sur la Législation Française des Faillites et Banqueroutes avant 1673, tesis doctoral, Université de Rennes, Rennes, 1903. pp. 47-48. Michel DE JUGLART y Benjamin IPOLITO confunden a Armand Guillon con L. Guillou, atribuyendo a este último la referida tesis doctoral de Guillon, equivocando también en el título la fecha de la Ordenanza de 1673 y situándola en 1793 (en Traité de droit commercial. Procédures collectives de paiement, Paris, 1998, vol. 6, p. 7, nota 9).
} 
en mercados o subastas públicas-. En cuanto al procedimiento, precisamos que en la Ordenanza de Carlos VIII de 1490 se imponía al deudor que iba a llevar a cabo la cesión la obligación de comparecer personalmente para evitar fraudes a los acreedores (salvo que estuviese impedido), al igual que en otras posteriores aunque habría excepciones ${ }^{7}$. La solicitud se presentaba ante el juez del domicilio del deudor y si se trataba de una cesión voluntaria tan sólo se requería la homologación del contrato ${ }^{8}$. Debía el solicitante declarar detalladamente su activo y pasivo y, en algunas costumbres, un juramento de la imposibilidad de pagar y del compromiso de pago en el futuro, se establecía como formalidad añadida ${ }^{9}$. Más adelante se exigiría dar publicidad a la cesión - con independencia de que fuera voluntaria o judicial- mediante anuncios colocados en lugares públicos que, a veces, eran los juzgados y en otras ocasiones la Iglesia más próxima ${ }^{10}$. La liquidación que seguía a la cesión se proyectaba sobre la totalidad del patrimonio del deudor; en consecuencia, éste debía ceder todos sus bienes. Si algún elemento de la masa concursal era retenido por un acreedor, debía ser devuelto bajo pena de perder su parte en el precio del objeto. En un principio, las diferentes fases de la liquidación estaban en manos de la justicia, pero poco a poco se fue dejando mayor campo de acción a los acreedores - que solían nombrar un curador, con independencia de que

\footnotetext{
${ }^{7}$ Armand GuILloN, Essai historique sur la Législation Française des Faillites et Banqueroutes avant 1673, pp. 52-53; Claude DuPOUY, Le droit des faillites en France avant le Code de Commerce, pp. 14-15.

${ }^{8}$ Para Jean Marie PARDESSUS la voluntaria tenía su razón de ser, de un lado, en el ofrecimiento por parte del deudor $\mathrm{y}$, de otro, en la aceptación por los acreedores pudiéndose incluso pactar la extinción total de la deuda. Si hay unanimidad en la aceptación ni siquiera sería necesaria la homologación. Para ser anulada la cesión el acreedor debe demostrar que el deudor ha retenido alguna cosa. Tendria todos los efectos de una venta en el supuesto en que las partes hubiesen querido una dación en pago. Al margen de este supuesto no quedaría el deudor privado de su propiedad sino sólo del derecho a disponer y, en caso de fallecimiento, su heredero tan sólo recuperaría la propiedad del bien pagando a los acreedores. Cualquier excedente de la venta debe entregarse al deudor. Las formalidades a las que ha de someterse la venta serán tan sólo las convenidas entre las partes (Corso di Diritto mercantile, versión italiana de Annibale CAllegarI, vol. III, Venezia, 1841, pp. 302-303). Claude DupouY resalta que, tras la homologación, la voluntad de la mayoría de acreedores se impone a la minoría disidente (Le droit des faillites en France avant le Code de Commerce, tesis doctoral, Université de Paris, Paris, 1960, p. 19).

${ }^{9}$ Armand Guillon, Essai historique sur la Législation Française des Faillites et Banqueroutes avant 1673, pp. 53-54.

${ }^{10}$ Claude Dupouy, Le droit des faillites en France avant le Code de Commerce, pp. 15-16; Armand GuILLON, Essai historique sur la Législation Française des Faillites et Banqueroutes avant 1673, p. 54.
} 
estuviese o no previsto- ejerciendo la autoridad una mera supervisión e imponiéndose el derecho privado".

La costumbre de Orléans dedica sus artículos 424, 428 y 429 al tratamiento de la materia referente a los beneficios de la cesión y de la espera $^{12}$. En el derecho consuetudinario francés se hace referencia a la cesión de bienes y a las cartas de crédito como también a las distintas formas de ejecución sobre bienes muebles e inmuebles a la hora de llevarse a cabo la cesión ${ }^{13}$. La insuficiencia de bienes muebles hace recurrir a los inmuebles ${ }^{14}$; por tanto, se debe acudir siempre, en primer lugar a los muebles aunque el deudor haya vinculado especialmente un concreto bien inmueble. Se distingue una ejecución sobre muebles ordinarios y aquella dirigida frente a cosechas no recogidas, por su carácter aun inmobiliario. La ejecución ordinaria no reviste mayores dificultades cuando los muebles están ya en posesión del acreedor, en concepto de prenda, pues - en tal caso- tan sólo necesita obtener un permiso de venta procedente del juez, incluso es posible que en los primeros tiempos vendiese por sí mismo sin más formalidades ${ }^{15}$. Si no tiene la posesión se efectúa el embargo y, salvo oposición, la venta se llevará a cabo en ocho días y el deudor podía siempre obtener la restitución de los muebles embargados ofreciendo otros de igual valor ${ }^{16}$. El problema

\footnotetext{
"Armand GuILlon, Essai historique sur la Législation Française des Faillites et Banqueroutes avant 1673, pp. 59-60.

"Ver comentarios de J. POTHIER, Coutume d'Orléans, vol. I, Paris, 1845, ch. III, n" 122 128 , pp. $627-630$.

${ }^{13} \mathrm{~F}$. Olivier-Martin, Histoire de la coutume de la prévôté et vicomté de Paris, Paris, 1926 , vol. II, pp. 555-565 y 592-593 de la $1^{\text {a }}$ ed. y 589-599 y 626-627 de la $2^{a}$.

${ }^{14}$ Respecto a los bienes inmuebles se requería el permiso del deudor para proceder a su embargo, ya que estaba presente la idea de que estos bienes pertenecían más a la familia que al individuo, escapando así de la persecución de los acreedores que sólo contaban con vías indirectas para actuar contra el deudor, como por ejemplo la ejecución personal consistente en el encarcelamiento del deudor hasta el pago de la deuda (Claude DupouY, Le droit des faillites en France avant le Code de Commerce, p. 8).

${ }^{15}$ En algunas costumbres, según precisa Claude DuPOuY, por ejemplo en la Coutume de Charroux, pequeña población entre Poitiers y Limoges, próxima a Civray, el acreedor podía tomar por sí mismo los bienes muebles de su deudor, derecho que sería consagrado por una Ordenanza de Luis VI del año 1134 y limitado más tarde a los deudores extranjeros. A veces, el embargo consistía en la entrega de los bienes a los acreedores, asimilándose entonces a la cesión (Le droit des faillites en France avant le Code de Commerce, pp. 5-6).

${ }^{16} \mathrm{~F}$. OLIVIER-MARTIN, Histoire de la coutume de la prévôté et vicomté de Paris, vol. II, $1^{\mathrm{a}}$ ed., p. 558 y $2^{\mathrm{a}}$, p. 592 . Ver también sobre las formalidades de la ejecución sobre los bienes con base en diferentes Ordenanzas, Armand GuILlON, Essai historique sur la Législation Française des Faillites et Banqueroutes avant 1673, pp. 36-39 y respecto al principio de igualdad entre los acreedores consagrado en el art. 178 de la Costumbre de Paris, como base
} 
radica en saber qué tipo de bienes muebles se pueden llegar a embargar por parte de la autoridad judicial o municipal; así, por ejemplo, el Style du Châtelet de Paris ${ }^{17}$ habla de que no se puede embargar el lecho en las siguientes condiciones: $1^{\circ}$ ) en función de la edad del deudor, es decir si ha alcanzado ya la senectud; $2^{\circ}$ ) en el supuesto de que esté casado y sea padre de familia; $3^{\circ}$ ) si es de poco valor; $4^{\circ}$ ) si el deudor es un hombre que vive entre estrecheces y calamidades económicas que lo sumen en una profunda miseria. Resultan, igualmente, inembargables conforme al Style du Châtelet, $1^{\circ}$ ) una mesa de nogal (nos asombra la especificación del material como si solamente quedara excluida esta modalidad y no ninguna otra; ¿acaso es que en el siglo XV en París el nogal era el material más utilizado para la construcción de las mesas de las casas de los particulares? No hemos podido comprobar este supuesto), $2^{\circ}$ ) una parrilla de hierro, $3^{\circ}$ ) dos platos, $4^{\circ}$ ) ocho cuencos de estaño ${ }^{18}$. Si el embargado era un clérigo que ha contraído obligaciones, vinculando sus bienes temporales, habrá que adoptar las medidas necesarias para salvaguardar la prestación de sus servicios ${ }^{19}$. El deudor puede oponerse al embargo que grava con la indisponibilidad absoluta todo o parte de su patrimonio. Esta oposición debe realizarse en el momento oportuno, con suficiente fundamento, y no como un medio de ganar tiempo. Para que sea recibida se exige que el deudor "tranquilice" a los acreedores consignando una suma suficiente para garantizar el pago del crédito en conflicto. En este caso, los bienes pueden ser devueltos al deudor hasta que se resuelva la oposición ${ }^{20}$. El Style du Châtelet y el Style des Maucreux, entre otros textos, permiten la oposición cuando el deudor hace cesión de bienes o cuando es retenido en prisión ${ }^{21}$ y la Grand Coutumier

para otras posteriores, pp. 40-45.

${ }^{17} \mathrm{~F}$. OLIVIER-MARTIN recoge el texto muy abreviado, en Histoire de la coutume de la prévôté et vicomté de Paris, vol. II, la ed., p. 558, nota 6 y 2a , p. 592, aunque no lo glosa; el comentario es nuestro.

${ }^{18}$ Cfr. F. Olivier-Martin, Histoire de la coutume de la prévôté et vicomté de Paris, vol. II, $1^{\mathrm{a}}$ ed., p. 558 , nota 6 y $2^{\mathrm{a}}$, p. 592 .

${ }^{19} \mathrm{~F}$. Olivier-Martin, Histoire de la coutume de la prévôté et vicomté de Paris, vol. II, $1^{\mathrm{a}}$ ed., p. 555 y $2^{\text {a }}$, p. 589.

${ }^{20} \mathrm{~F}$. OlIVIER-Martin, Histoire de la coutume de la prévôté et vicomité de Paris, vol. II, $1^{\text {a }}$ ed., p. 555 y $2^{a}$, p. 589 . La exigencia de garantía para levantar el embargo es recogida en otros textos y sentencias referidos por OLIVIER-MARTIN, $1^{\mathrm{a}}$ ed., pp. 555-556 y $2^{\mathrm{a}}$, pp. 589-590.

${ }^{2}$ F. Olivier-Martin, Histoire de la coutume de la prévôté et vicomté de Paris, vol. II, 1"a ed., p. 555 , nota 8, y $2^{a}$, p. 589. 
sólo admite invocar para sustraerse a la ejecución tres excepciones, falsedad de las letras, pago, o pacto de non petendo ${ }^{22}$. La oposición podía proceder de un tercero, propietario de la cosa embargada. El procedimiento ejecutivo se tenía que llevar a cabo sin interrupción y si se paralizaba durante un año y un día era obligado volver a comenzar ${ }^{23}$. No se admiten dos ejecuciones contra un mismo deudor sobre los mismos bienes, de forma que el segundo acreedor sólo puede obtener el pago oponiéndose a la primera ejecución. En este punto es importante distinguir según que el deudor esté o no arruinado, es decir si es o no totalmente insolvente. Las reglas de la distribución en caso de ruina se fijaron por el derecho consuetudinario desde 1317 . Se solía entender que existía ruina cuando no se disponía de bienes para afrontar el pago tras una primera ejecución. En este caso, el acreedor que instaba el procedimiento ejecutivo no gozaba de ningún privilegio, sino tan sólo del derecho a que se hiciera deducción de los gastos invertidos por él, antes de repartir la totalidad de los bienes entre todos los acreedores en función de la cuantía respectiva de las deudas. Del mismo modo se procedía en caso de cesión de bienes en favor de un sólo acreedor. El principio del reparto proporcional sólo se aplicaba al producto obtenido de la venta de muebles, ya que respecto a los inmuebles los acreedores hipotecarios ocupaban un lugar preferente, al igual que otros créditos que, pese a la ruina, conservaban su carácter privilegiado. Por el contrario, si el deudor es solvente el acreedor más diligente es preferido al resto, siempre que no se ocasionen perjuicios a los demás ${ }^{24}$.

La espera en el derecho francés recibe los nombres de répit y de délai d'ajournement o simplemente délai, que poseen el mismo significado y se utilizan indistintamente para indicar el correspondiente instituto jurídico que se concede al deudor que no tiene liquidez para satisfacer a sus acreedores y requiere de un plazo de tiempo para alcanzarla. Las cartas moratorias españolas son las lettres de répit francesas. El procedimiento para la solicitud de las mismas - que no excedían de cinco años- se hacía por

\footnotetext{
${ }^{22} \mathrm{~F}$. OLIVIER-MARTIN, Histoire de la coutume de la prévôté et vicomté de Paris, vol. II, $1^{\text {a }}$ ed., p. 556 y $2^{\mathrm{a}}$, p. 590.

${ }^{23} \mathrm{~F}$. OLIVIER-MARTIN, Histoire de la coutume de la prévôté et vicomté de Paris, vol. II, $1^{\text {a }}$ ed., p. 556 y $2^{\mathrm{a}}$, p. 590.

${ }^{24} \mathrm{~F}$. OLIVIER-MARTIN, Histoire de la coutume de la prévôté et vicomté de Paris, vol. II, $1^{\mathrm{a}}$ ed., pp. 556-557 y $2^{\mathrm{a}}$, pp. 590-591.
} 
vía judicial, según el art. 61 de la Ordenanza de Orléans ${ }^{25}$. Se prohiben -según los arts. 424, 428 y 429 de la Costumbre de Orléans- a los extranjeros y en ciertos casos en los que la ley las estima indignas, por ejemplo deudas de pensiones, alimentos, medicinas, alquiler (incluso cuando este último debe pagarse en especie); salarios de la servidumbre, jornales de artesanos, depósitos, etc. ${ }^{26} \mathrm{La}$ incompatibilidad entre este aplazamiento y el beneficio de la cesión de bienes se recoge en algunas costumbres francesas, por el mismo carácter de último recurso que tenía la cesión ${ }^{27}$. Parecidas, aunque una particular modalidad de este instituto jurídico de las lettres de répit, son las denominadas lettres d'État, que el rey otorga a los oficiales de los ejércitos de tierra y mar y para los funcionarios importantes de la Administración del Estado a quienes puede conceder el beneficio de una moratoria en sus deudas. Presentan, entre otras, numerosas características como la de otorgarse por un tiempo de seis meses; tienen un carácter amplio no exclusivamente reducido al apremio por parte de los acreedores, sino que también pueden extenderse a toda clase de procedimientos en que se vieran implicados los bienes muebles e inmuebles. Su concesión tan sólo permite el embargo preventivo, no judicial, de bienes inmuebles. Si se había procedido a embargo judicial antes de la notificación de las lettres, se mantiene y si éste expiraba durante el periodo de moratoria, se puede

\footnotetext{
${ }^{25}$ Ya con posterioridad una Ordenanza de 1669 , tít. 6, arts. 1 y 2 , derogó esta costumbre en razón de que, al tratarse de una concesión graciosa, debían de emanar de la autoridad real, aunque el juez puede, en determinadas circunstancias, aplazar la ejecución por un periodo que no exceda de tres meses o supervisar los acuerdos entre las partes implicadas (J. POTHIER, Traité de la procédure civile, vol. X de Oeuvres, ch. III, $\mathrm{n}^{\circ} 715, \mathrm{pp} .340-341$ ).

${ }^{26} \mathrm{~J}$. POTHIER, Traité de la procédure civile, vol. X de Oeuvres, ch. III, n 716, p. 341. Ver sobre las lettres de répit lo indicado, también por POTHIER en Coutume d'Orléans, vol. I de Oeuvres, ch. III, $\S$ II, $\mathrm{n}^{\circ} 128-134$, pp. 628-629. Afirma que se solian conceder cuando la iliquidez del deudor tenía su origen en un acontecimiento imprevisto, probando la autenticidad de este extremo $\left(n^{\circ} 130\right)$. Su principal efecto era paralizar la ejecución en el plazo de seis meses, hasta que fueran ratificadas, $y$, una vez confirmadas, durante el periodo por el que se concedieran. Así, el acreedor no podía dirigirse contra la persona del deudor, ni embargar muebles de uso cotidiano, pero las lettres no impedían el embargo de otros muebles, ni de inmuebles, sin que pudiesen, no obstante, antes de la expiración del plazo, proceder a la venta, salvo que se tratase de muebles perecederos - se llevaría a cabo, todo lo más, una anotación preventiva de embargo $\left(n^{\circ} 134\right)$ -

${ }^{27}$ Armand Gulloon, Essai historique sur la Législation Française des Faillites et Banqueroutes avant 1673, pp. 56-57. Para Jean HILAIRE las lettres de répit constituian no un impedimento respecto a la cesión, sino un remedio para la misma por el mismo carácter infamante que revestía esta última (Introduction historique au droit commercial, Paris, 1986, p. 316). Sobre las oscilaciones de la jurisprudencia consultar Claude DUPOUY, Le droit des faillites en France avant le Code de Commerce, p. 17.
} 
constituir uno nuevo. Igualmente continúan las subastas ya comenzadas. El alto funcionario público puede renunciar, mediante contrato, a las lettres d'État, pero no a la facultad de recurrir a las cartas moratorias o al beneficio de cesión. Además las primeras no están sujetas a la ratificación y no impiden acceder a la función pública como las lettres de répit o la misma cesión $^{28}$.

En Francia existía una costumbre por parte de los jueces consistente en colocar un gorro verde en la cabeza de los quebrados y de aquellos que eran admitidos al beneficio de cesión. Tenía el sentido de una verdadera infamia y era de carácter consuetudinario, siendo su fin principal intimidar a los ciudadanos a llevar a cabo una buena gestión de sus negocios ${ }^{29}$. Posteriormente se eximía de la cesión infamante a los deudores que carecían totalmente de culpa. Era habitual que el deudor anunciase en alta voz que llevaba a cabo la cesión de bienes ${ }^{30}$. El ceremonial, tal y como se hacía, aparecía rodeado de un carácter humillante ${ }^{31}$, habida cuenta de que se realizaba en público en un lugar destacado y con el propósito no tanto de una garantía con respecto a los acreedores sino de un cierto menosprecio del deudor, hasta el punto de que si el guardia municipal, llegado al domicilio o lugar de trabajo de este último, no hallaba bienes muebles suficientes para hacer frente a las deudas podía proceder a poner a buen recaudo en prisión al deudor.

La privación de libertad del deudor podía revestir dos modalidades, de un lado la prohibición de salir de la ciudad, lo cual le permitía continuar con sus actividades o la prisión propiamente dicha. Esta última fue la más corriente, pero era posible que el prisionero la evitase si juraba no abandonar París. No se solía encarcelar a la mujer por deudas salvo que tuviesen su origen en ferias o mercados. En realidad, esta prisión no proporcionaba

\footnotetext{
${ }^{28}$ J. POTHIER, Coutume d'Orléans, ch. III, \& II, n” 135, pp. 629-630. Sobre las lettres de répit y las d'État ver también Armand GuILLON, Essai historique sur la Législation Française des Faillites et Banqueroutes avant 1673, pp. 64-73.

${ }^{29} \mathrm{~J}$. POTHIER, Traité de la procédure civile, vol. X de Oeuvres, ch. II. n 713, pp. 338-339. Aclara que no sería conforme a la equidad imponer esta condición al que cae en la indigencia por una mala fortuna.

${ }^{30}$ Claude Dupouy, Le droit des faillites en France avant le Code de Commerce, p. 15.

${ }^{31} \mathrm{~F}$. Olivier-MarTin, Histoire de la coutume de la prévôté et vicomté de Paris, vol. II, p. 564 de la $1^{\mathrm{a}}$ ed. y p. 598 de la $2^{\mathrm{a}}$, nota 1 . Ya se había ocupado de la materia J. BRISSAUD Manuel d'histoire du Droit français à l'usage des étudiants en licence et en doctorat. Paris. 1898 , p. 1472.
} 
ninguna satisfacción al acreedor, sino que tenía una finalidad coactiva para que pusiese todos sus esfuerzos en pagar o, en su caso, llevase a cabo la cesión de bienes. Una vez encarcelado, normalmente, no solía oponer excepción al acreedor sino que aceptaba la condena del juez a pagar en un breve plazo. A veces podía obtener de los acreedores un aplazamiento, siempre que ofreciese garantía suficiente, aunque esto no era frecuente. Si el prisionero no obtenía una liberación temporal o fracasaba en sus intentos de saldar la deuda podía recurrir a la cesión de bienes con el oportuno juramento ${ }^{32}$.

La Costumbre de Saint-Sever contiene algunas prescripciones en materia de ejecución, manifestando, en su art. 28 , la preferencia a la hora de llevar a cabo el embargo por los bienes muebles frente a los inmuebles. Muestra un rechazo a la cesión de bienes, precisamente por las formalidades humillantes que la acompañaban, de forma que aparece calificada como «miserabile remedium» que sólo queda reservado al que ha actuado con malicia o fraude y no le queda otro recurso conforme a derecho ${ }^{33}$.

El heredero que no ha hecho el inventario no se admite al beneficio de cesión ob dolum presumtum; y los arrendatarios tampoco frente a los propietarios. En este sentido hay una amplia doctrina francesa sostenida sobre todo por la Jurisprudencia y una decisión judicial que indica esta imposibilidad. Otros casos exceptuados de la cesión era el de los tutores a los que no se permitía este beneficio, ni a los que fuesen depositarios de bienes de la justicia ${ }^{34}$, o los depositarios y administradores en general de cara a la restitución de los bienes que le han sido confiados y según el art. 429 de la Costumbre de Orléans, los comisionistas ${ }^{35}$. Tampoco se admitía la cesión de bienes en favor de aquél que mantuviera algún tipo de obligaciones o de deudas cuando éstas habían sido contraídas en las ferias de

${ }^{32} \mathrm{~F}$. Olivier-Martin, Histoire de la coutume de la prévôté et vicomté de Paris, vol. II, p. 562-563 de la $1^{\text {a }}$ ed. y pp. 596-597 de la $2^{a}$.

${ }^{33}$ Michel Marechal y Jacques Poumarede, La Coutume de Saint-Sever, Paris, 1988, pp. 45 y $78-81$.

${ }^{34}$ Armand GuILLON, Essai historique sur la Législation Française des Faillites et Banqueroutes avant 1673, p. 55. La exclusión de los tutores y arrendatarios era cuestionada por POTHIER, pese a su base jurisprudencial, y, más tarde legal respecto al tutor, entendiendo que debía limitarse a los casos de mala fe (Traité de la procédure civile, vol. X de Oeuvres, ch. II, $n^{0} 711$, pp. 335-336). Respecto a los arrendatarios de granjas estimaba necesario probar su actitud dolosa aplicando los frutos obtenidos en su propio provecho en lugar de pagar el precio del arrendamiento (Coutume d'Orléans, ch. III, \$ I, n⿳124, pp. 627-628).

${ }^{35}$ J. POThiER, Traité de la procédure civile, vol. X de Oeuvres, ch. II, n²711, p. 335. 
Lyon, o de la Champagne (no se consideran otras convocatorias de mercaderes como las celebradas cuatro veces al año en Perpignan, o las que tenían lugar en Carcassonne), aunque hay quien afirma que la aplicación es generalizada para todas las deudas contraídas en ferias e incluso para aquéllas derivadas de actos de comercio $^{36}$. La imposibilidad de cesión respecto a deudas reales y con origen en ferias podía ser excepcionada por el rey como una concesión de favor ${ }^{37}$. Se excluyeron igualmente los extranjeros que no habían obtenido la carta de naturalización francesa, tanto respecto a acreedores franceses, como al deudor francés en relación a un acreedor extranjero ${ }^{38}$. Del mismo modo no gozan del beneficio los que pierdan sus derechos civiles ${ }^{39}$ y los deudores que hubieran actuado de forma dolosa o fraudulenta, ni mucho menos cuando la deuda consista en la responsabilidad civil derivada de un delito $0^{40}$-aunque esto último no reviste novedad alguna-. La razón fundamental en que se basan la mayor parte de las excepciones era que el beneficio de cesión se configuraba como de Derecho Público y no depende, pues, de un acuerdo entre particulares. Pero, por más que se trate en este punto de distanciar el Derecho romano del

\footnotetext{
${ }^{36}$ Armand GuILlon, Essai historique sur la Législation Française des Faillites et Banqueroutes avant 1673, pp. 57-58. Sobre la quiebra en las ferias ver pp. 81-97. En cuanto a las deudas que tenían su origen en las ferias de Champagne y el procedimiento colectivo de ejecución de las mismas ver Jean HILAIRE, Introduction historique au droit commercial, pp. 314-315. Respecto a las ferias de Champagne, Brie y Lyon y el ius mercatorum, Claude DupouY, Le droit des faillites en France avant le Code de Commerce, pp. 34-51. En el art. 428 de la Costumbre de Orléans no se permite la cesión cuando la deuda va referida al precio de los productos adquiridos en un mercado público como ganado, vino, trigo, pescado, etc. En el art. 439 se determina lo mismo respecto a los compradores de bienes muebles e inmuebles en pública subasta. La razón radica en la fe pública que impera en mercados y subastas y que haría incurrir en actitud dolosa al que no acude con dinero disponible para llevar a cabo sus adquisiciones. Cuando el vendedor empieza a conceder crédito a sus compradores, desaparece la antedicha razón y empieza a admitirse el beneficio de cesión (J. POTHIER, Traité de la procédure civile, vol. X de Oeuvres, ch. II, n"711, p. 336).

${ }^{37} \mathrm{~F}$. Olivier-MARTIN, Histoire de la coutume de la prévôté et vicomté de Paris, vol. II, p. 564 de la $1^{\mathrm{a}}$ ed. y p. 598 de la $2^{\mathrm{a}}$.

${ }^{38}$ Armand GUILLON, Essai historique sur la Législation Française des Faillites et Banqueroutes avant 1673, p. 55. Excluye PARDESSUS a los extranjeros que tienen en el país establecimiento con autorización regia y no se muestra de acuerdo con la reciprocidad apuntada por Guillon, ya que la cesión de un francés a un extranjero debe ser examinada por un Tribunal francés (Corso di Diritto mercantile, versión italiana de A. CALLEGARI, vol. III, p. 305). Partidario de la reciprocidad es Claude DuPOUY, Le droit des faillites en France avant le Code de Commerce, p. 17.

${ }^{39}$ Claude Dupouy, Le droit des faillites en France avant le Code de Commerce, p. 16. Señala como ejemplo los condenados a penas de galeras con carácter perpetuo.

${ }^{40} \mathrm{~J}$. POTHIER, Traité de la procédure civile, vol. X de Oeuvres, ch. II, n” 711, p. 336.
} 
histórico francés, éste fue el sentido establecido por parte de las leyes romanas $^{4 !}$, y la filosofía inspiradora del mismo (en buena parte de su evolución presente).

En el derecho de los Países Bajos existe esta institución desde que fue recibida en el condado de Hainaut a partir del siglo XIV, extendiéndose en el siglo XV a Brabante. En el desarrollo del procedimiento de cesión coincidente con el modelo francés - de cuyo buen funcionamiento responde el deudor - hay una salvaguarda de formalidades que comportan la presentación de la solicitud que conlleva el que el deudor pueda realizar la misma directamente ${ }^{42}$ o bien solicitar, conforme al derecho francés, a la Cancillería Real cartas que le autoricen para pedir la cesión, llevando a cabo una valoración de cuál es la situación económica del negocio que va a facultar a recurrir a este mecanismo. Este era el modo de proceder habitual y las lettres se concedían de forma automática, según un modelo tipo que comenzaba exponiendo los motivos de la solicitud (cuya extensión dependía de la voluntad del deudor) ${ }^{43}$. En un principio, tal y como se recoge en las costumbres de Amberes y de Hainaut, el deudor tenía que estar previamente encarcelado para que se admitiese la cesión. No obstante, pronto se admitirá este remedio con carácter preventivo, en concreto, por Carlos V, en su Ordenanza de $1536^{44}$. En esta norma, en la que no vamos a entrar por quedar ya al margen de nuestro trabajo, se desarrollará detalladamente el procedimiento. Nos permitimos apuntar que la instrucción de la demanda

\footnotetext{
${ }^{41}$ D. 42,3 y C, 7,71 .
}

${ }^{42}$ Indica F. OLIVIER-MARTIN que - a finales del siglo XIV - en Francia se podía hacer el abandono sin necesidad de "letras reales", de forma que el deudor prisionero no tenía más que emplazar a su acreedor el viernes, día de misericordia, para hacerle la cesión (Histoire de la coutume de la prévôté et vicomté de Paris, vol. II, p. 563 de la $1^{\text {a }}$ ed. y p. 597 de la $2^{\mathrm{a}}$ ). Al emplazamiento en viernes alude también Claude DuPOUY, Le droit des faillites en France avant le Code de Commerce, p. 14.

${ }^{43}$ Véronique DEMARS-SiON, Contribution à l'histoire de la faillite: étude sur la cession de biens à la fin de l'Ancien Régime, en "Revue historique de droit français et étranger", LXXV/I (enero/marzo, 1997), pp. 40-41. En todo caso el deudor debía dejar claros tres puntos, la ausencia total de responsabilidad, su incapacidad para pagar, y las amenazas que le acechaban. Refiere Philippe GODDING que la cesión se practicaba en muchas localidades, al margen de las "letras" desde el siglo XV (Le droit privé dans les Pays-Bas méridionaux du 12e au 18e siècle, Bruxelles, 1987, p. 519).

${ }^{44}$ Señala J.M. PARDESSUS que la simple demanda de cesión no permite al deudor, ya encarcelado, obtener de forma interina su libertad (Corso di Diritto mercantile, vol. III, pp. 306-307). Claude DUPOUY indica que en las costumbres de Lille y Douai el deudor se mantenía encarcelado mientras se decidía si se le admitía o no la cesión (Le droit des faillites en France avant le Code de Commerce, p. 16). 
venía adornada con una serie de formalidades simbólicas: el deudor se quitaba el sombrero y el cinturón ante el juez, representándose así no sólo la pérdida de los bienes, sino también del honor. Este ritual venía impuesto en Francia por la Ordenanza de Luis XII de 1510 y anteriormente por una sentencia de 25 de mayo de $1453^{45}$. Si nadie se oponía, eran ratificadas al instante, pero si algún acreedor se mostraba en contra se debía resolver el asunto de forma sumaria en un plazo de cuatro meses aproximadamente, al término del cual era emplazado el deudor ${ }^{46}$.

Dentro de la doctrina francesa, Jacques de Révigny ${ }^{47}$ poco avanzó en su momento en la consideración de los medios de reacción contra la ejecución personal de los deudores y la regulación jurídica al respecto. El embargo de bienes es analizado en varios de los comentarios, que en forma de quaestiones disputatae, escribió Révigny, pero Kees Bezemer se ha detenido sobre este particular ${ }^{48}$ y no sobre la cesión de bienes. Es a Jacques de Révigny, obispo de Verdún, a quien se debe atribuir la obra que, bajo presunta autoría de Pierre de Belleperche (fallecido en 1308 en Auxerre), lleva por título Lectura insignis et fecunda super prima parte Codicis et super secunda parte Codicis $^{49}$. Comenta la rúbrica del Codex relativa a la

\footnotetext{
${ }^{45} \mathrm{Cfr}$. Armand Guillon, Essai historique sur la Législation Française des Faillites et Banqueroutes avant 1673, pp. 49-50. p. 519

${ }^{46} \mathrm{Philippe}$ Godding, Le droit privé dans les Pays-Bas méridionaux du 12e au 18 e siècle,

${ }^{47}$ Ver los trabajos sobre este autor de C.H. BEZEMER, A Repetitio by Jacques de Révigny on the Creations of the Ius Gentium, en "Tijdschrift voor Rechtsgeschiedenis", XLIX/3-4 (1981), pp. 287-321 y Les 'Quaestiones disputatae orléanaises' dans les commentaires de Jacques de Révigny, en “Tijdschrift voor Rechtsgeschiedenis”, LVIII/1-2 (1990), pp. 5-38; Kees BEZEMER, Legal Remedies for Non-Roman Law in Medieval Doctrine. The 'condictio ex consuetudine' and Similar Actions, en "Tijdschrift voor Rechtsgeschiedenis", LX/1-2 (1992), pp. 63-80, particularmente sobre Révigny las pp. 66-71 y sobre la tradición de la Escuela de Orléans, pp. 71-73; French Customs in the Commentaries of Jacques de Révigny, en "Tijdschrift voor Rechtsgeschiedenis”, LXII/2 (1994), pp. 81-112 y What Jacques saw. Thirteenth century France through the eyes of Jacques de Révigny, professor of law at Orléans, Frankfurt am Main, 1997 y Anne M. Halley, Arts, Law and Other Studies in Orléans in the Twelfth, Thirteenth and Fourteenth Centuries, tesis doctoral, City University of New York, New York, 1979, pp. 146-153.

${ }^{48}$ What Jacques saw, pp. 25, 33, 55, 60, 70, 91, 98, 104, 105, 112 y 134.

${ }^{49}$ Cfr. E.M. MeIJers, Études d'histoire du droit, Leyden, 1959, vol. III, pp. 73-74 (ver también el conjunto de las pp. 59-80) y Anne M. HALLEY, Arts, Law and Other Studies in Orléans in the Twelfth, Thirteenth and Fourteenth Centuries, pp. 149-150, siguiendo MEIJERS. Sobre Pierre de Belleperche ver pp. 153-154, donde apunta que gran parte de su pensamiento sería recogido por Bartolo da Sassoferrato (1314-1357) al que Baldo degli Ubaldi (1327-1400) reprochaba que se hubiese apropiado de sus ideas sin referirlo entre sus fuentes. Kees BEZEMER en The Law School of Orléans as School of Public Administration, publicado en "Tijdschrift
} 
cesión de bienes. Refiere la consabida obligación del deudor de completar el pago de sus deudas si viene a mejor fortuna y el efecto liberatorio de la prisión de forma que si decide no pagar, ni ceder sus bienes, será enviado a la cárcel donde es mantenido y durante cuarenta días lacerado y difamado y pasados los cuales se entregaba a los acreedores - aunque recoge opiniones contrarias a la entrega-. Sobre la necesidad de que el deudor estuviese condenado o confeso sigue a Azzo. Plantea también la discusión en cuanto al objeto de la cesión y la posibilidad de reservarse los vestidos de uso ordinario, estimando poco verosímil que el deudor pudiese aparecer públicamente desnudo, lo que resultaría bastante irreverente. Aborda el problema relativo a si la cesión puede resultar liberatoria de una obligación de hacer, por ejemplo, cuando un sujeto se obliga contractualmente a escribir un libro y no lo hace, siendo enviado a prisión por tal incumplimiento. Concluye que no es admisible, en este caso, que ceda sus bienes, ya que entre autores hay diferencias sustanciales y se contrata en virtud de las características particulares del que debe hacer la obra. Niega, con carácter

voor Rechtsgeschiedenis”. LXVI/3-4 (1998), pp. 247-277, muestra a su vez la influencia de Belleperche, profesor en Orléans, que también estuvo en Bolonia y fue deán de la Catedral de Paris y Obispo de Auxerre, en Cino da Pistoia (1270-1336). Ni HALLEY, ni C.H. BEZEMER, ni Kees BEZEMER nada dicen sobre las glosas de Belleperche a C. 7,71 y D. 42, 3. Pierre LEGENDRE había ya mostrado la relación de deuda que Cino da Pistoia tenía respecto a Révigny y Belleperche, indicando que aquél citaba a los dos maestros de Orléans y que Cino fue el intermediario a través del cual Bartolo tuvo conocimiento de los franceses (La France et Bartole, en "Bartolo da Sassoferrato. Studi e documenti per il VI Centenario", Milano, 1962, vol. I, pp. 131-172). En los dos volúmenes del espléndido homenaje a la figura de Bartolo sorprende que los estudios institucionales, salvo los referentes a la teoría estatutaria, el origen del derecho internacional privado, la soberanía y una contribución sobre los pactos sucesorios, brillan por su ausencia. No se apuntan soluciones algunas al tema de la insolvencia, que no existe en las mil doscientas sesenta páginas dedicadas al que fuera profesor del Studium Generale de Perugia. La suerte de Révigny está asociada tan directamente a Bartolo, que la ed. de sus Lecturae super Institutionibus de Milano, 1506, aparece bajo el nombre del profesor perusino, error que también puso de manifiesto MEIJERS, Études d'Histoire du droit, vol. III, p. 68. Sobre el particular consultar igualmente, Peter WEIMAR, Die Erstausgabe der sogenannten Lectura Institutionum des Pierre de Belleperche, en "Tijdschrift voor Rechtsgeschiedenis", XXXV/3-4 (1967), pp. 284-290. No era infrecuente este tipo de falsas paternidades de obras. Pierre LEGENDRE recoge en Une oeuvre faussement atribuée a Bartole, en "Revue historique de droit français et étranger", vol. L (1964), p. 704, la falsa atribución a Bartolo del De carceribus de Matteo Mattesillani en la edición de Lyon, 1538, tal y como se demuestra por el examen del ms. 2098, fols. 59v y 62r de la Biblioteca Episcopal de la Seo de Urgell. Domenico MAFFEI en Bartolomeo da Novara (†1408) autore della 'Lectura Institutionum' attribuita a Baldo degli Ubaldi, en "Rivista di storia del diritto italiano", LXIII (1990), pp. 5-22 demuestra la atribución a Baldo degli Ubaldi de la Lectura Institutionum (en las eds. de Köln, 1447; Lyon, 1478; Pavia, 1489 y 1495; Milano, 1493; Venezia, 1496 y 1500) de Bartolomeo de Novara, así como del Tractatus percussionum de Odofredo a Bartolo da Sassoferrato. Ver también del propio Domenico MAFFEI, Il 'Tractatus percussionum' pseudo-bartoliano e la sua dipendenza da Odofredo, en "Studi senesi", 78 (1966), pp. 7-18. 
general, la cesión en las obligaciones de hacer ${ }^{50}$. El deudor puede arrepentirse de la cesión efectuada y decidir pagar aunque Révigny no admite la posibilidad de que cambie nuevamente de decisión y vuelva a ceder $^{51}$. Una vez cedidos los bienes no se permite que los acreedores lleven a cabo el reparto por sí mismos sino que el juez debe ordenar la venta y hasta ese momento el deudor puede recuperar sus bienes pagando la deuda, salvo que se haya realizado una dación en pago ${ }^{52}$. Prácticamente inexistente es el comentario a la cesión de bienes efectuada con la finalidad de eludir las funciones municipales ${ }^{53}$. Respecto a las formalidades precisa que, en Lombardía, existía la costumbre de que el cedente manifestara su voluntad de ceder sin camisa, golpeado en la espalda y recibiendo el rechazo de todo el pueblo ${ }^{54}$. Analiza igualmente la cesión de los filiifamilias ${ }^{55}$ y las mayorías exigidas para el acuerdo entre acreedores atinente a la concesión de la moratoria de cinco años, teniendo en cuenta los créditos privilegiados, negando, con carácter general, la cesión al deudor que ya ha gozado del beneficio de la espera salvo que, una vez transcurridos los cinco años, no pague y los acreedores decidan admitirle la cesión dado que pueden obtener más beneficio de ésta que del envío a la cárcel del deudor ${ }^{56}$.

Enfoca la cesión de bienes el jurista de Lyon Guy Pape (14021476) desde el efecto no liberatorio de la deuda total hasta que mejore la situación económica del deudor. Más que un estudio del derecho romano efectúa ciertas incursiones en la práctica de Lyon, donde era costumbre

\footnotetext{
${ }^{50}$ Jacques de RÉVIGNY [Pierre de Bellerperche], Lectura insignis et fecunda super prima parte Codicis et super secunda parte Codicis, Paris, 1519 (reimp. anastática, Bologna, 1967), ad C. $7,71,1$, fol. $369 v$. Nada comenta sobre la cesión de bienes, ni la insolvencia y responde más a un planteamiento general sobre el comentario al Codex, H. KIEFNER, Zur gedruckten Codexlectura des Jacques de Révigny, en "Tijdschrift voor Rechtsgeschiedenis", XXXI/1-2 (1963), pp. 5-38.

${ }^{51}$ Jacques de RÉvIGNY, Lectura super prima parte Codicis et super secunda parte Codicis, ad C. 7, 71, 2, fol. 369v.

${ }^{52}$ Jacques de RÉviGNY, Lectura super prima parte Codicis et super secunda parte Codicis, ad C. 7, 71, 4, fol. 369v.

${ }^{53}$ Jacques de RÉvignY, Lectura super prima parte Codicis et super secunda parte Codicis, ad C. 7, 71, 5, fol. 369v.

${ }^{54} \mathrm{Jacques}$ de RÉVIGNY, Lectura super prima parte Codicis et super secunda parte Codicis, ad C. $7,71,6$, fol. $369 \mathrm{v}$.

${ }^{55}$ Jacques de RÉviGNY, Lectura super prima parte Codicis et super secunda parte Codicis, ad C. 7, 71, 7, fol. 370r.

${ }^{56} \mathrm{Jacques}$ de RÉvignY, Lectura super prima parte Codicis et super secunda parte Codicis, ad C. $7,71,8$, fol. $370 \mathrm{r}$.
} 
golpear al cedente - quien se encontraba expuesto al público sobre una piedra especialmente destinada al efecto - al igual que en otras localidades. Esta categoría despreciable de cesión - de la que muchos reniegan - sí tenía efectos plenamente liberatorios, según indica Pape, aunque posteriormente el deudor prosperase económicamente. Recoge el pensamiento del jurista de Rimini Matteo Bruno ${ }^{57}$ en cuanto a no admitir la cesión en caso de fraude, dolo o solvencia del deudor o cuando éste ha disfrutado de la moratoria quinquenal. Refiere además la necesidad de que se efectúe personalmente y no mediante procurador ${ }^{58}$.

La relación entre bancarrotas y cesiones y las condiciones en las que la mujer puede llevar a cabo la cesión se plantean por parte de un autor tan clásico del derecho francés, aunque más conocido por su producción literaria que como abogado, como Gabriel Bounyn, quien se ocupa también de la obligación impuesta al que hacía cesión de bienes de llevar un gorro verde. La cuestión es si la mujer estaba o no exenta de la misma ${ }^{59}$.

El desarrollo ulterior en los siglos modernos es otra cuestión de la que no vamos a ocuparnos, ya que el homenaje a la profesora Regina Sáinz de la Maza Lasoli, a quien dedicamos esta colaboración, y en el que estamos muy honrados de participar, se circunscribe a la época medieval que ella, en los temas de instituciones eclesiásticas, cultivó con tanta soltura y elegancia como reconocimiento en España y en Italia.

\section{RÉSUMÉ}

La cession de biens est l'abandon qu'un débiteur fait de tous ses biens à ses créanciers. La procédure fut introduite en France avec les Établissements de Saint Louis (1256). Son principal intérêt consiste à permettre à l'insolvable d'échapper à la prison. Dans les Pays-Bas la procedure est similaire.

\footnotetext{
${ }^{57}$ De cessione bonorum, en Tractatus illustrium in utraque tum pontificii, tum caesarei iuris facultate Iurisconsultorum universi iuris, Venezia, 1575; Venezia, 1584, tomo III, part. 2, fols. 179-204.

${ }^{58}$ Guy PAPE, Commentaria in statutum Delphinale, Lyon, 1507, q. 343, pp. 595-596.

${ }^{59}$ Les cessions et banqueroutes; et les causes qui ont meu le sage et souverain Sénat et Parlement de Paris de confirmer le jugement du juge de Laval, sur ce qu'il aurait condammé un cédant aux biens de porter le bonnet ou chapeau verd; et sçavoir s'il se peut donner à tous cédants indiféremment; et si aux femmes, au susdit cas, l'on peut donner le chapperon verd ou autre marque, Paris, 1586.
} 


\section{SUMMARY}

The cessio bonorum is the surrender of all his property made by an insolvent debtor for the benefit of his creditors. The process was introduced in France with the Etablissements de Saint Louis (1256). The insolvent avoided the prison. It is his principal interest. The process is similar in Netherlands and Belgium. 